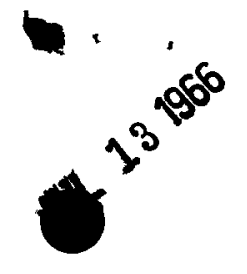

$$
\begin{aligned}
& \text { LA-DC-7781 (Full Paper) } \\
& \text { CoNf-660608-9 }
\end{aligned}
$$

IN NUCLEAR SCIENCE ABSTRACTS

\title{
REVIEW OF TRANSFER FUNCTION MEASUREMENTS IN THE NUCLEAR ROCKET PROGRAM USING NOISE TECHNIQUES
}
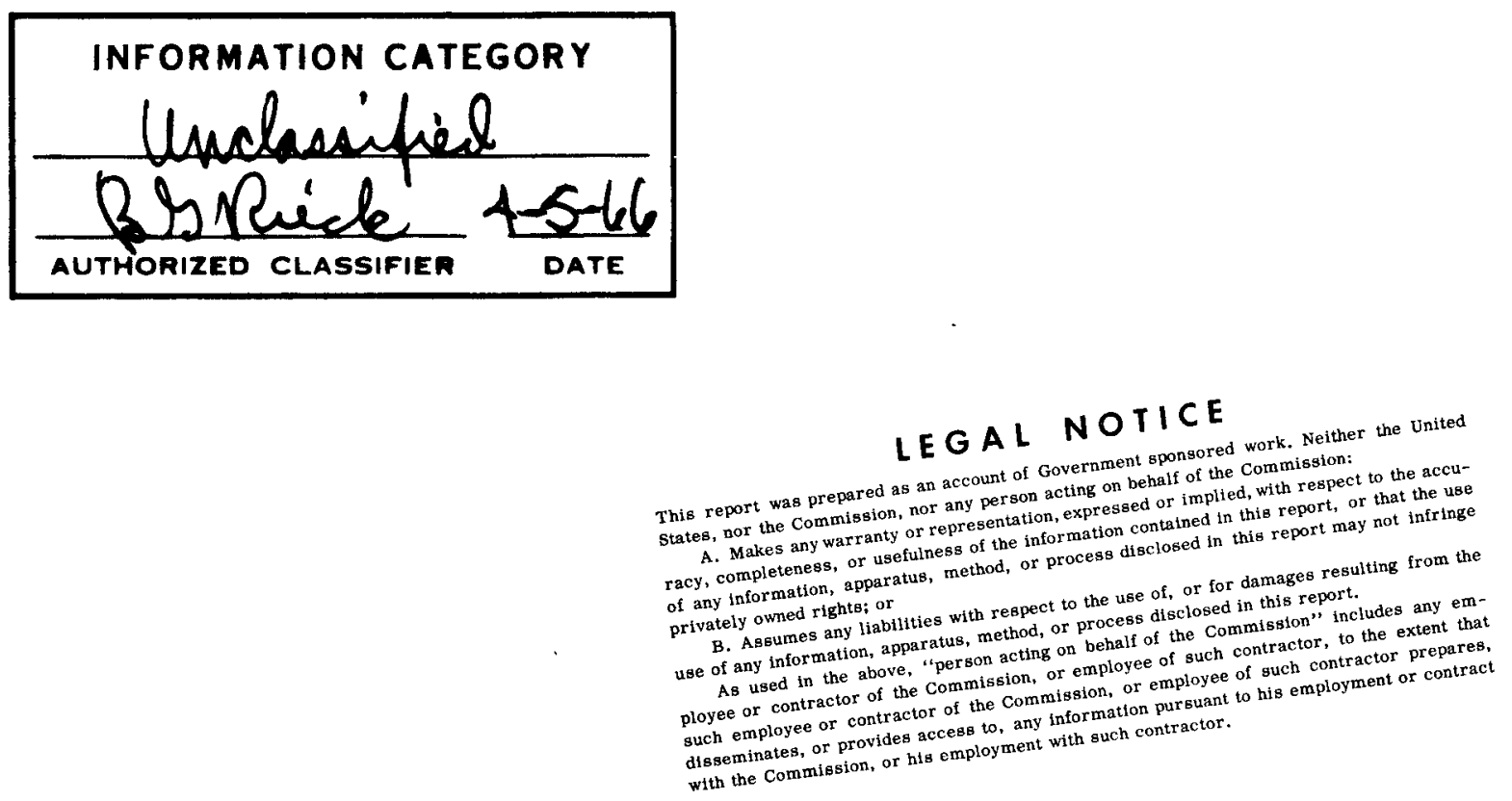


\section{DISCLAIMER}

This report was prepared as an account of work sponsored by an agency of the United States Government. Neither the United States Government nor any agency Thereof, nor any of their employees, makes any warranty, express or implied, or assumes any legal liability or responsibility for the accuracy, completeness, or usefulness of any information, apparatus, product, or process disclosed, or represents that its use would not infringe privately owned rights. Reference herein to any specific commercial product, process, or service by trade name, trademark, manufacturer, or otherwise does not necessarily constitute or imply its endorsement, recommendation, or favoring by the United States Government or any agency thereof. The views and opinions of authors expressed herein do not necessarily state or reflect those of the United States Government or any agency thereof. 


\section{DISCLAIMER}

Portions of this document may be illegible in electronic image products. Images are produced from the best available original document. 


\title{
REVIEW OF TRANSFER FUNCTION MEASUREMENTS \\ I \\ IN THE NUCLEAR ROCKET PROGRAM USING NOISE TECHNIQUES*
}

\author{
A. A. Wasserman, J. D. Balcomb, C. A. Bodenschatz, J. A. Johnson, \\ G. H. Steiner, T. E. Springer, L. R. James, and E. K. Honka** \\ University of California, Los Alamos, New Mexico \\ Westinghouse Electric Corporation, Pittsburgh, Pennsylvania
}

\begin{abstract}
This paper summarizes the body of experience in transfer function measurements using noise techniques which has been acquired by the Los Alamos Scientific Laboratory (LASL) and the Westinghouse Astronuclear Laboratory (WANL) during several series of nuclear rocket reactor tests at the Nuclear Rocket Development Station (NRDS) in Nevada. Such measurements, using random or pseudo-random input signals and cross-correlation data processing techniques, have been performed by LASL during testing of the KIWI-A3, KIWI-B-4D, KIWI-B-4E, and Phoebus-IA reactor systems, and by WANL during testing of the NERVA Reactor Experiments NRX-A2, NRX-A3, and NRX/EST. The purposes of these measurements were to aid in control system design and checkout and to aid in validation of dynamic computer models used to predict overall system performance.
\end{abstract}

* Program administered by the Space Nuclear Propulsion Office, a joint office of the U.S. Atomic Energy Commission and the National Aeronautics and Space Administration.

** A. A. Wasserman, Manager, Systems Integration Department, Astronuclear Laboratory.

J. D. Balcomb, Staff Member, Group N-4, Los Alamos Scientific Laboratory.

C. A. Bodenschatz, Supervisor, System Dynamics Experiments, Astronuclear Laboratory.

J. A. Johnson, Staff Member, Group N-4, Los Alamos Scientific Laboratory.

G. H. Steiner, Senior Engineer, System Dynamics Experiments, Astronuclear Laboratory.

T. E. Springer, Staff Member, Group N-4, Los Alamos Scientific Laboratory.

E. K. Honka, Senior Engineer, Control Systems Engineering, Astronuclear Laboratory.

L. R. James, Senior Engineer, System Dynamics Experiments, Astronuclear Laboratory. 


\section{INTRODUCTION}

This paper summarizes the body of experience in transfer function measurements using noise techniques which has been acquired by the Los Alamos Scientific Laboratory (LASL) and the Westinghouse Astronuclear Laboratory (WANL) during several series of nuclear rocket reactor tests at the Nuclear Rocket Development Station (NRDS) in Nevada. Such measurements, using random or pseudo-random input signals and cross-correlation data processing techniques, have been performed by LASL during testing of the KIWI-A3, KIWI-B-4D, KIWI-B-4E, and Phoebus-IA reactor systems, and by WANL during testing of the NERVA Reactor Experiments NRX-A2, NRX-A3, and NRX/EST. The purposes of these measurements were to aid in control system design and checkout and to aid in validation of dynamic computer models used to predict overall system performance.

\section{TEST SETUP AND PROCEDURES}

Figure 1 is a schematic drawing of the nuclear rocket reactor test system, applicable to all tests mentioned except NRX/EST. For NRX/EST (NERVA Reactor Experiment/Engine System Test), the hydrogen gas to drive the turbine was derived from the mixing of a hot bleed stream drawn from the core exit and a cooler bleed stream drawn from the core inlet, rather than from the separate gas supply shown in figure 1.

In the transfer function measurements, the input noise-like signal was applied during steady-state operation either to (a) the control loop which adjusts the angular position of the reactivity-control drums located in the reflector region of the reactor or (b) to the control loop which adjusts the position of the turbine inlet gas valve and thereby controls the turbopump speed and the flow of liquid hydrogen coolant to the reactor and thrust nozzle.

The theory of the method and the reasons for choosıng noise-like input signals with cross-correlation of input and output, over other methods of transfer function measurements (e.g. , sinusoids, steps, or autocorrelation of inherent fluctuations) have been discussed previously 1,2. Briefly, this method gives results over a given frequency spectrum in the least amount of test time; i.e., of the order of the system settling time. In addition, it requires only small amplitude perturbations, so that it is not hazardous, is not limited by system nonlinearities, and does not interfere with normal system operation. Finally, it can be used even in the presence of strong noise sources, provided the correlation time is increased beyond the system settling time. 
In the balance of this paper, each of the major studies mentioned above will be described briefly and typical results presented to illustrate the types of useful information which have been obtained from these measurements. Also summarized are several significant analytical studies and laboratory experiments which helped in understanding how to apply the methods used.

KIWI-A3 Test

In the KIWI-A3 test performed by LASL in October 1960, a pseudo-random binary input signal was applied to the reactivity control loop during steady-state operation at low power $(10 \mathrm{KW})$, and to the power control loop during steady-state operation at full power 1 . An on-line analog cross-correlator was used to compute the cross-correlation function (and impulse response) of the system. The impulse response was then digitally converted to the system transfer function by Laplace transformation. From the low power measurements performed with an input signal having 1019 bits per sequence, a bit frequency of $20 \mathrm{cps}$, and a reactivity amplitude of $\pm 7 \not$, a value for the prompt neutron lifetime was derived $\left(4 \times 10^{-4}\right.$ sec) which agreed fairly well with the value obtained using sinusoidal oscillation techniques. From the high power measurements performed with an input signal having 251 bits per sequence, a bit frequency of $50 \mathrm{cps}$, and a net power swing of \pm 1 percent, the transfer function of the power control system at full power was derived. Figure 2 shows the impulse response and figure 3 the transfer function of the power control system at full power determined in this test.

Analytical and Laboratory Studies

In 1963, a digital computer study ${ }^{3}$ was performed at LASL (a) to compare the accuracy of results obtained with random and with pseudo-random input signals applied to simple firstorder and second-order systems, and (b) to study the effects of background system noise on the accuracy of measurement. It was found that, with a record length of 2.5 seconds for systems with a characteristic break frequency of 100 cps, a Gausslan input signal gave significantly poorer results for the impulse response than a pseudo-random binary input signal. Furthermore, with the Gaussian signal, use of the cross-spectral density as an estimate of the transfer function gave very poor results, unless the results were divided by the autospectral density of the input. With the pseudo-random signal and correlation over an integral number of cycles of the input signal, good results would be obtained without division by the autospectral density of the input. In the presence of background noise, it was found that the rms error in the 
impulse response was proportional to the square root of the cross-correlation integration time. With a signal-to-noise ratio of unity at the system output and using only one cycle of a pseudo-random input signal, good results were obtained for the impulse responses of the two test systems.

In the spring of 1964, analog computer studies ${ }^{4}$ were performed at WANL (a) to obtain experience in the operation of a feedback-shift-register generator for the production of pseudo-random binary signals, (b) to evaluate the effect on the accuracy of impulse response measurements of varying the ratio of the period of the input pseudo-random signal to the settling time of a simple, second-order test system, (c) to study the effect of background noise on measurement accuracy, and (d) to compare results for the impulse response of a complex analog model of the NRX-A2 liquid hydrogen feedsystem obtained by cross-correlation with a pseudo-random input signal, with those obtained by applying an impulse-like input signal directly to the model. From these studies it was concluded that for reasonable accuracy, the period of the applied input signal should be at least twice the settling time of the system. It was also confirmed that with a signal-to-noise ratio of unity at the system output, good results can be obtained with a single cycle of a pseudo-random input signal. For smaller values of signal-to-noise ratio, more than one cycle of the input signal would be required to obtain good results. Finally, the measurement of the impulse response of the NRX-A2 feedsystem model with pseudo-random excitation was in excellent agreement with the results obtained with impulse excitation.

In May 1964, a series of low power transfer function measurements was conducted jointly by WANL and LASL on the PARKA critical facility reactor at LASL 5,6. The PARKA reactor was a low-power mockup of the KIWI-B-4A reactor, including a similar power control system. In these measurements, a WANL-designed pseudo-random signal generator ${ }^{7}$ was used to apply a perturbation in the demand signal at several points in the power control loop. The resulting control drum position and power level were cross-correlated with the input signal, and various transfer functions associated with the power control loop were calculated. From these experiments it was concluded (1) that the signal generator performed accurately and reliably, (2) that accurate transfer function results could be obtained using this technique, with a precision at each frequency of better than $\pm 1.5 \mathrm{db}$ in gain and \pm 9 degrees in phase, and (3) that results for the transfer function of the control drum actuator were in good agreement with results obtained by the sinusoidal technique. 
The KIWI-B-4D reactor was tested on 13 May 1964. Although no external noise signal was introduced into the reactor, fluctuations did occur in the test which allowed some powerto-core temperature transfer function information to be deduced from the recorded data. The feedback signal used in the temperature control loop of the KIWI-B-4D reactor was the core exit gas temperature as measured by a thermocouple passed through the nozzle wall. Due to boundary variations in the gas stream, these thermocouple readings fluctuated appreciably. The temperature control loop response to this erratic feedback signal resulted in power fluctuations up to a maximum of $310 \mathrm{MW}$ peak-to-peak. The test was terminated prematurely due to a failure of the regeneratively cooled nozzle tubes.

The fluctuations did provide an opportunity to obtain some indication of the dynamic response of the temperatures at various positions in the core to variations in power. Two time intervals, each 12 seconds in duration, were analyzed using the cross-correlation method in order to obtain transfer functions throughout the reactor core. Because of the limited data sample interval, the analysis covered only a narrow frequency band. These analyses did show fair agreement with the mathematical models then in use and gave confidence to the concept of using in-core thermocouples for reactor control.

\section{KIWI-B-4E Test}

During the full power hold of the restart of the KIWI-B-4E reactor in August 1964, a gaussian noise signal with an upper cutoff frequency of approximately $0.3 \mathrm{cps}$ was fed into the temperature control system in order to cause power perturbations in the reactor ${ }^{8}$. The purpose was to obtain a measurement of the power-to-core-temperature transfer functions over a broader band of frequencies than was possible in the KIWI-B-4D test. Some 60 seconds of data were analyzed by the cross-correlation method. Because the temperature responses amounted to only about 0.1 percent of the normal channel ranges, special zero-suppression channels with added amplification were used to suppress the large, unwanted $d-c$ component and to amplify the remaining, small, time-varying component. Typical peak-to-peak swings of the power and core temperature were approximately $67 \mathrm{MW}$ and $20^{\circ} \mathrm{R}$, respectively, with rms values of $10.6 \mathrm{MW}$ and $5^{\circ} \mathrm{R}$, respectively. In processing the data, numerical filtering was used to smooth the data. 
Figures 4 and 5 show the resulting transfer functions measured from power to temperature at various core axial stations over a frequency band from 0.025 to $0.7 \mathrm{cps}$. In this range the precision was estimated with 90 percent confidence to be better than $2.3 \mathrm{db}$ in magnitude and 17 degrees in phase, with much better precision in the decade from 0.025 to $0.25 \mathrm{cps}$. Analysis of non-zero-suppressed data channels, having much larger relative noise levels, gave surprisingly good results out to $0.25 \mathrm{cps}$, underscoring the effectiveness of the crosscorrelation method. From the results obtained at a given axial core station but different radial stations, it was concluded that if there were any radial dependence of the transfer function, it was less than $3 \mathrm{db}$ in magnitude and less than 35 degrees in phase from 0.03 to 0.25 cps. The measured transfer function at a given station had values intermediate between those calculated for the fueled and unfueled graphite portions of the core by means of models then available.

From the results obtained, it was concluded that (a) this type of measurement could be conducted without interference with other test objectives or distraction to the operators; (b) excellent temperature recordings could be obtained with extreme (factor of 45,000 ) amplification of thermocouple emfs; (c) qualitatively useful results could be obtained from normal range temperature recordings for perturbation levels of 0.1 percent of full scale, al though reliance on these recordings alone was not recommended; (d) the data obtained were directly useful in subsequent temperature controller design; and (e) general agreement between mathematical predictions and measurements was obtained over the frequency range of importance.

NRX-A2 Test

In the NRX-A2 tests in September-October 1964, a pseudo-random binary input signal, produced by the feedback-shift-register generator that had been tested in the PARKA experiments, was used to perturb both the turbopump speed control loop and the power control loop during close to full power operation. Response measurements were made of pressures, temperatures, and flow rates at various points within the feedsystem, nozzle, and reactor, along with measurements of the power level and the valve and drum positions ${ }^{2}$. Although the results derived from these data were limited by the need for improved ranging of a number of the data channels, the primary objective of the measurements was met; namely, to demonstrate that pseudo-random signals with amplitudes near background noise levels could be applied to the NERVA reactor system during steady-state holds and meaningful system transfer function results derived, without interfering with other test objectives. In addition, the 
experience gleaned from the NRX-A2 test series permitted major improvements in data acquisition and data processing techniques in preparation for the NRX-A3 cross-correlation measurements.

$\underline{\text { NRX-A3 Test }}$

During the NRX-A3 test series in January-May 1965, two sets of pressure transfer function measurements were made which yielded good results 9,10 . The first of these measurements was made during a feedsystem checkout test in which the reactor and nozzle were replaced by an orifice at the end of the liquid hydrogen feedline. The orifice was sized to have the same impedance at full flow as the reactor and nozzle assembly. In this test, a flow rate of $41 \mathrm{lb} / \mathrm{sec}$ of liquid hydrogen was established, and a pseudo-random signal with 511 bits per sequence and a bit frequency of $100 \mathrm{cps}$ was applied for 23 seconds to the turbopump speed demand, producing a peak-to-peak variation in turbine speed of $\pm 600 \mathrm{rpm}$. Measurements of the fluctuating components of the turbine power control valve position, turbine speed, pump exit pressure, pump discharge flow rate, and feedline exit pressure permitted the determination of the transfer functions relating these variables. The peakto-peak variation in flow rate and feedline exit pressure were $\pm 3.5 \mathrm{lb} / \mathrm{sec}$ and \pm 20 psi, respectively. Measurements were also made with sinusoidal signals to permit a comparison of results by the two methods. The data were recorded on FM tape after passing through a high-pass filter to remove all frequency components below about $0.1 \mathrm{cps}$. Figures 6 and 7 show a comparison of cross-correlation results, sinusoidal results, and analog model predictions for the transfer function between turbine power control valve position and pump exit pressure.

The second set of pressure transfer function measurements was made during a steadystate hold at full power with the reactor and nozzle assembly tied in to the feedsystem. In this run a pseudo-random signal with 127 bits per sequence and a bit frequency of $12.5 \mathrm{cps}$ was applied to the turbine speed demand for 29 seconds of a planned 40 second run. (The run was truncated due to an unscheduled shutdown due to other causes.) Measurements were made of the pressure responses at the feedline exit, the inlet to the nozzle cooling tubes, the reflector inlet plenum, the core inlet plenum, and the nozzle thrust chamber (core exit). Figure 8 shows a comparison of the cross-correlation results with analog model predictions for the overall pressure-to-pressure transfer function from nozzle tube inlet to nozzle chamber. To demonstrate the consistency of the measurements, data points are included which were obtained by multiplying together the individual transfer functions of the several components in series. Also included are similar data taken during the Phoebus-IA tests described below. 
Phoebus-IA Test

\section{A. Pressure-to-Pressure Transfer Function Measurement}

During the Phoebus-IA full power test on 25 June 1965, pressure-to-pressure transfer function measurements were also made across the nozzle cooling tubes, the reflector, the core,

and the total system ${ }^{1 !}$. In these measurements, a pseudo-random signal was applied simul taneously to the flow rate demand and to the turbine speed demand in order to insure getting both low and high frequency components of the input signal into the inlet of the nozzle cooling tubes in spite of attenuations in the feedsystem. The input to the speed demand was fed through a pre-emphasis filter to provide some energy out to $10 \mathrm{cps}$. The pressure fluctuations were measured using a special acoustic $\Delta P$ transducer which automatically provides a zerosuppressed output signal with a low frequency cutoff at about $0.1 \mathrm{cps}$. The input signal had 511 bits per sequence and a bit frequency of 100 bits per second and was applied for 62.2 seconds. The peak-to-peak pressure fluctuations ranged from 17.5 psi at the nozzle inlet plenum (average value $890 \mathrm{psi}$ ) to $6.6 \mathrm{psi}$ at the core exit plenum (average value $545 \mathrm{psi}$ ). Figure 8 shows the measured transfer function from nozzle tube inlet to core exit. For frequencies out to $8 \mathrm{cps}$, the error in the results was calculated with 70 percent confidence to be less than $0.72 \mathrm{db}$ in magnitude and 5.2 degrees in phase.

\section{B. Power-to-Temperature Transfer Function Experiment}

A cross-correlation experiment very similar to that performed on the KIWI-B-4E reactor was also carried out on the Phoebus-IA reactor at NRDS on 25 June 1965. The experiment differed from the KIWI-B-4E experiment in the following respects:

1) The experiment utilized a pseudo-random signal instead of random noise as the test signal.

2) The core exit gas temperature was measured on Phoebus-IA, so that the response of this important variable was obtained in addition to the response of in-core thermocouples.

3) A new numerical method to filter out the low frequency drift in the measured data was devised and was successfully utilized in the data analysis.

4) The zero-suppressed temperature channels were recorded on a $\pm 200 \mathrm{O}$ range instead of a $\pm 30^{\circ} \mathrm{R}$ range. This decreased the probability of a channel drifting off scale during the experiment but also decreased the signal-to-noise ratio. 
5) The continuous duration of the experiment was 241 seconds instead of the 82 seconds obtained in KIWI-B-4E.

These changes, with the exception of 4 above, were all beneficial to the experiment. However, the reduction of a factor of six in the signal-to-noise ratio due to the range change of the data channels more than offset the benefits of the longer duration and ideal test signal characteristics. Thus the errors in the experiment, as measured by the coherence function, are significantly greater than the errors in the KIWI-B-4D experiment. The transfer function results for the in-core thermocouples are substantially in agreement with those measured in the KIWI-B-4E test but show a wider variance. They are shown in figure 9. The power-to-core exit gas temperature transfer function was also measured in this same experiment, and those results are shown on the same figure. As expected, the core exit gas temperature measurement shows an appreciably faster response than the in-core thermocouples.

In this experiment, the input signal to the temperature control loop was a pseudorandom binary signal of magnitude $\pm 15^{\circ} \mathrm{R}$, minimum switching frequency of 10 cycles per second and periodicity of 102.3 seconds (1023 bits per sequence). The response of the temperature control loop to this input produced power fluctuations of $13.4 \mathrm{MW}$, rms, or 1.3 percent of the total power. This, in turn, produced temperature fluctuations of $2.9^{\circ} \mathrm{R}$, rms, twenty inches from the core inlet, and $5.0^{\circ} \mathrm{R}$, rms, in the core exit gas. Significant drift was observed in the zero-suppressed temperatures. These data were numerically filtered to eliminate frequencies below $0.0125 \mathrm{cps}$ and above $2.5 \mathrm{cps}$ and to pass frequencies above $0.0625 \mathrm{cps}$ and below $1.25 \mathrm{cps}$. This eliminated much of the unwanted noise and drift.

NRX/EST Test

During the NRX/EST test series in December-March 1966, a large number of different cross-correlation transfer function measurements were made. These included $(a)$ low-power measurements of power control loop transfer functions for equipment checkout purposes, (b) intermediate-power $(\approx 230 \mathrm{MW})$ measurements of power-to-temperature transfer functions and measurements of the performance of a special no-flux-loop temperature control system, and (c) full-power measurements of power-to-temperature and pressure-to-pressure transfer functions, all using the methods previously developed. Figure 10 is a comparison of cross-correlation measurements and analog model predictions of the transfer function relating measured nozzle chamber temperature to the demanded value when operating with the no-flux-loop temperature control system. Other results at power were still being processed at the time of preparation of this paper. 


\section{CONCLUDING REMARKS}

The transfer function measurements made in the nuclear rocket program, using pseudorandom input signals and cross-correlation data processing, represent the first major application of this technique in a systematic manner for routine dynamic measurements in power reactor systems. As evidenced by the papers and discussions at the International Symposium on Neutron Noise, Waves, and Pulse Propagation at Gainesville, Florida, in February 1966, a number of other groups active in different areas of reactor technology have begun to interest themselves in applying this technique to their systems. These efforts are timely and indicate that the cross-correlation technique using pseudo-random signals has come of age.

Also worthy of note is the work which has been done during the past few years in the development of ternary pseudo-random signals for dynamic measurements 12,13 . Such signals can be used to measure higher-order kernels of non-linear systems. In addition, they are theoretically better suited for the measurement of linear approximation characteristics in the presence of non-linearities than binary pseudo-random signals. However, insufficient work has been done thus far to tell whether or not the gains in accuracy offered by the ternary signal in measurements of the linearized behavior of a non-linear system are significant enough in practical cases to suggest a change from the binary to the ternary signal at this time.

\section{REFERENCES}

1. J. D. Balcomb, H. B. Demuth, and E. P. Gyftopoulos, "A Cross-Correlation Method for Measuring the Impulse Response of Reactor Systems, "Nuc. Sci. and Eng., 11, $159-166$ (1961).

2. A. A. Wasserman, E. K. Honka, and G. H. Steiner, "Proposal for Measurement of NRX-A2 Reactor and Facility Transfer Functions by Cross-Correlation with PseudoRandom Binary Input Signals, "WANL-TME-757 (20 April 1964).

3. J. D. Balcomb, "Cross-Correlation Method of Measuring System Dynamic Response, " TID-7679 (June 1964).

4. E. K. Honka and G. H. Steiner, "Preliminary Analog Computer Study of the CrossCorrelation Impulse Response Measurement Technique to Determine Optimum Input Signal Characteristics," WANL-TME-1049 (21 May 1964).

5. J. F. Hafer, A. A. Wasserman, E. K. Honka, "Proposal to perform Transfer Function Measurements of the PARKA Critical Facility Reactor at LASL by Cross-Correlation with a Pseudo-Random Signal, "WANL-TME-793 (21 May 1964).

6. J. F. Hafer and E. K. Honka, Westinghouse Astronuclear Laboratory, Unpublished Results, May 1964. 
7. E. K. Honka, "Design of a Feedback-Shift-Register Pseudo-Random Signal Generator for Impulse Response Measurements, "WANL-TME-84I (18 June 1964).

8. J. D. Balcomb, "Measurement of the Power-to-Core Temperature Transfer Function of KIWI-B-4E, " AIAA Paper No. 65-615, Presented at AlAA Propulsion Joint Specialist Conference, Colorado Springs, Colorado, 14-18 June 1965.

9. G. H. Steiner, C. A. Bodenschatz, and A. A. Wasserman, "Transfer Function Measurements During the NRX-A3 Test Series," WANL-TME-1261 (August 1965).

10. A. A. Wasserman, G. H. Steiner, C. A. Bodenschatz, and E. K. Honka, "NERVA Reactor Transfer Function Measurements Using Cross-Correlation Techniques, " Proceedings of the International Symposium on Neutron Noise, Waves, and Pulse Propagation, Gainesville, Florida, 14-16 February 1966.

11. J. A. Johnson, "Measurement of Pressure-to-Pressure Transfer Functions Through the Phoebus-IA Nuclear Reactor, "Proceedings of the International Symposium on Neutron Noise, Waves, and Pulse Propagation, Gainesville, Florida, 14-16 February 1966.

12. E. P. Gyftopoulos and R. J. Hooper, "Signals for Transfer Function Measurements in Non-Linear Systems," TID-7679 (June 1964).

13. R. J. Hooper and E. P. Gyftopoulos, "On the Measurement of Characteristic Kernels of a Class of Non-Linear Systems, "Proceedings of the International Symposium on Neutron Noise, Waves, and Pulse Propagation, Gainesville, Florida, 14-16 February 1966. 


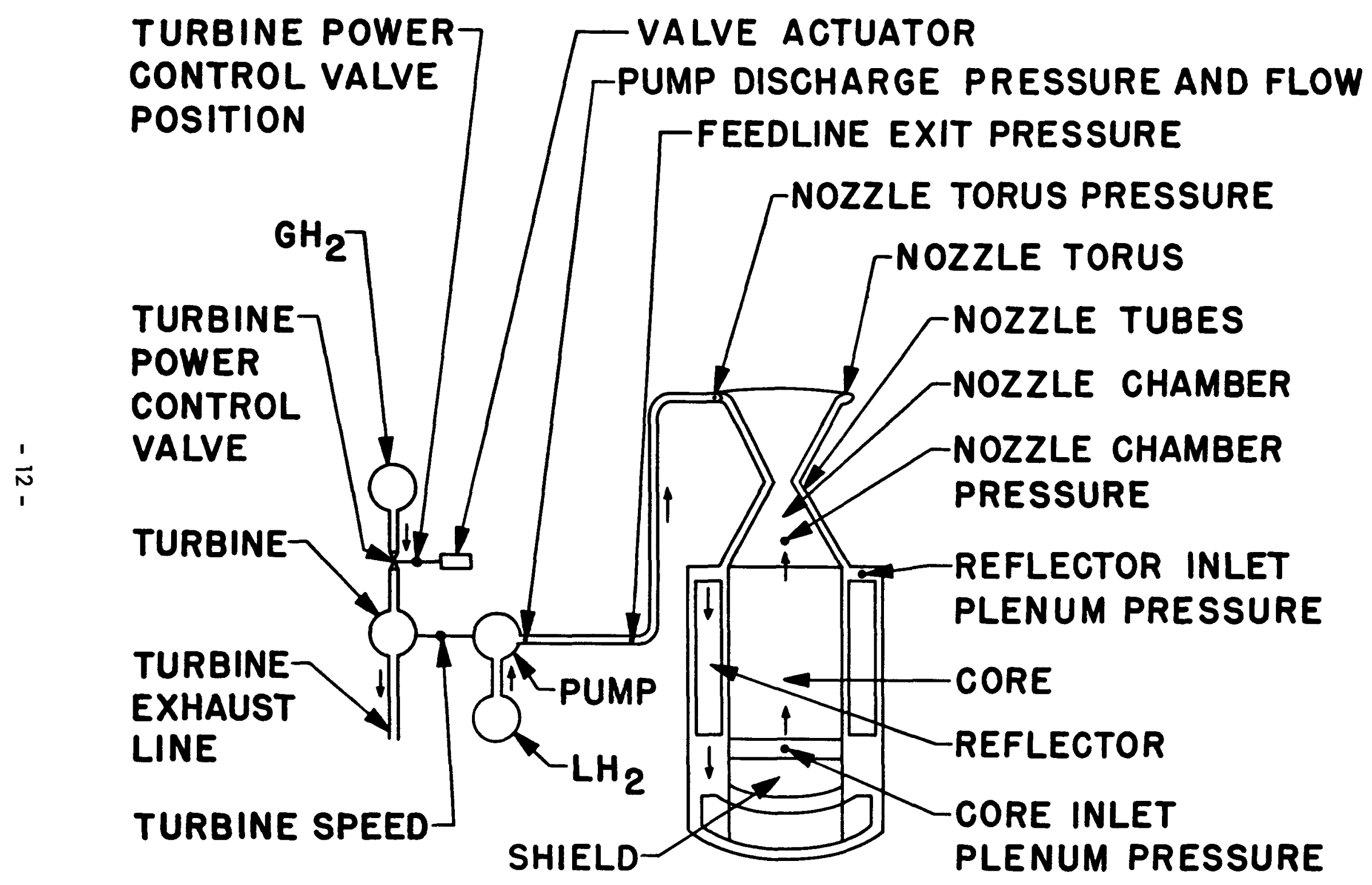

Figure 1. Schematic Drawing of Nuclear Rocket Reactor Test System 


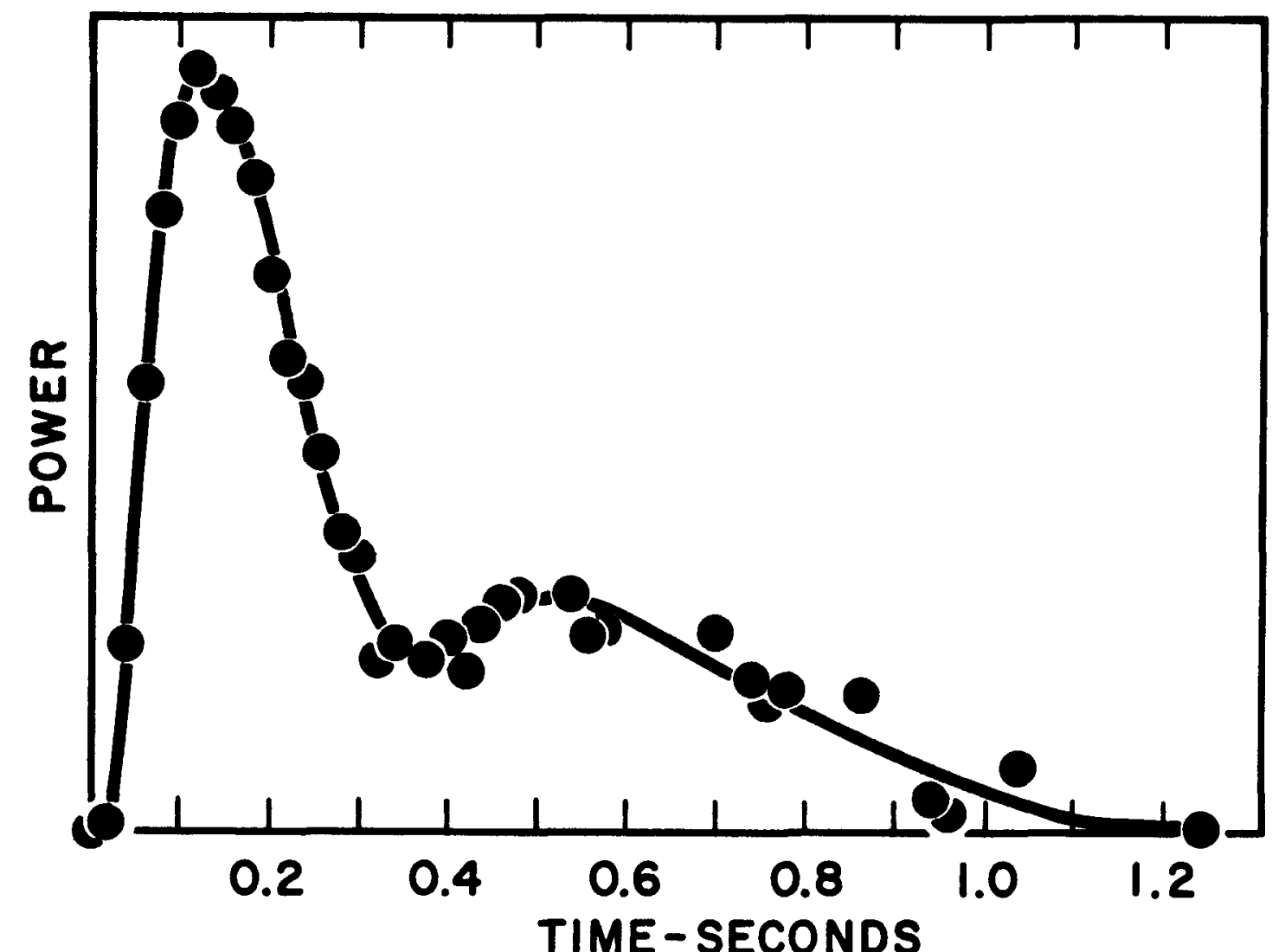

Figure 2. Impulse Response of the Control Loop as Measured by the Cross-Correlation Method with the Reactor at Full Power

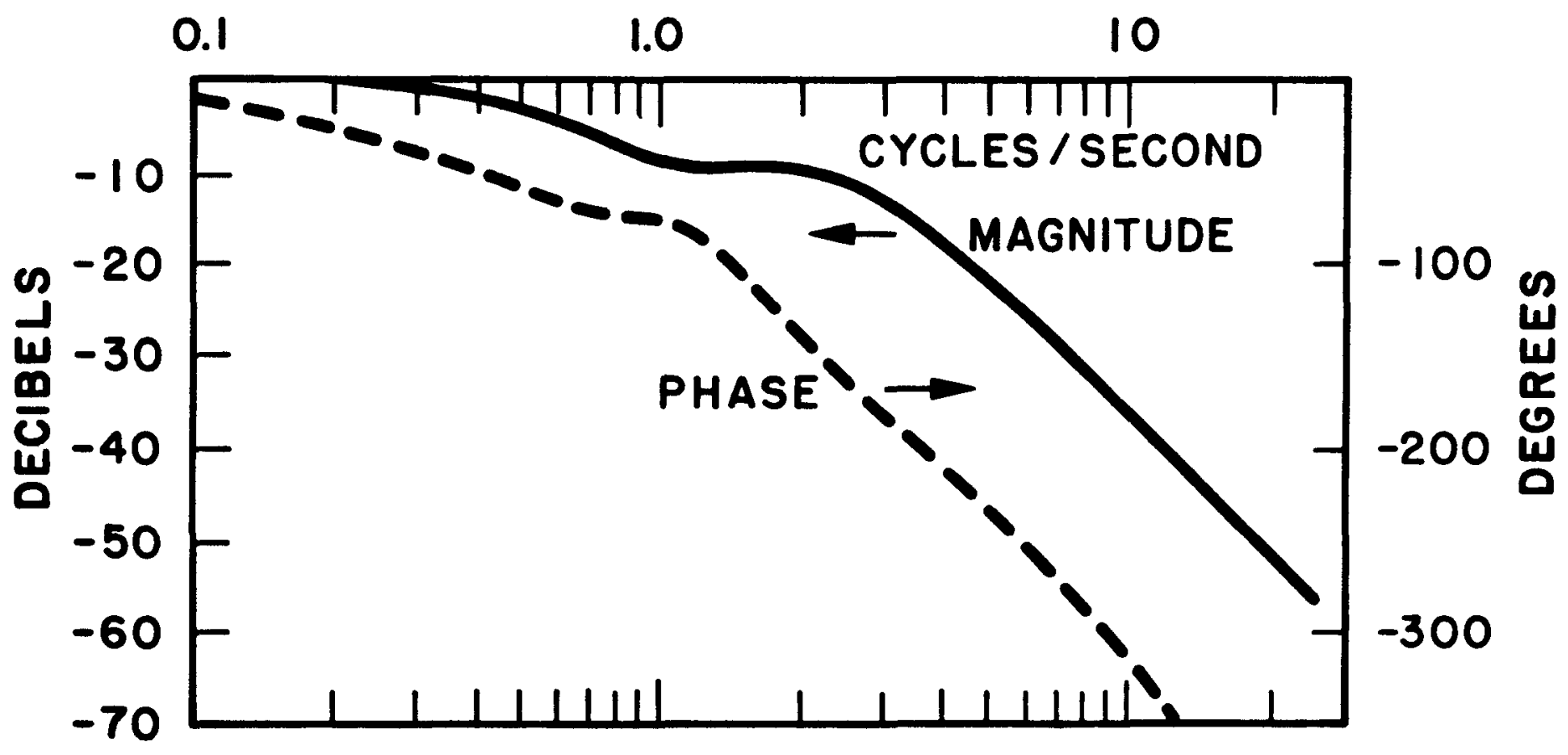

Figure 3. Transfer Function of the KIWI-A3 Power Control System at Full Power 


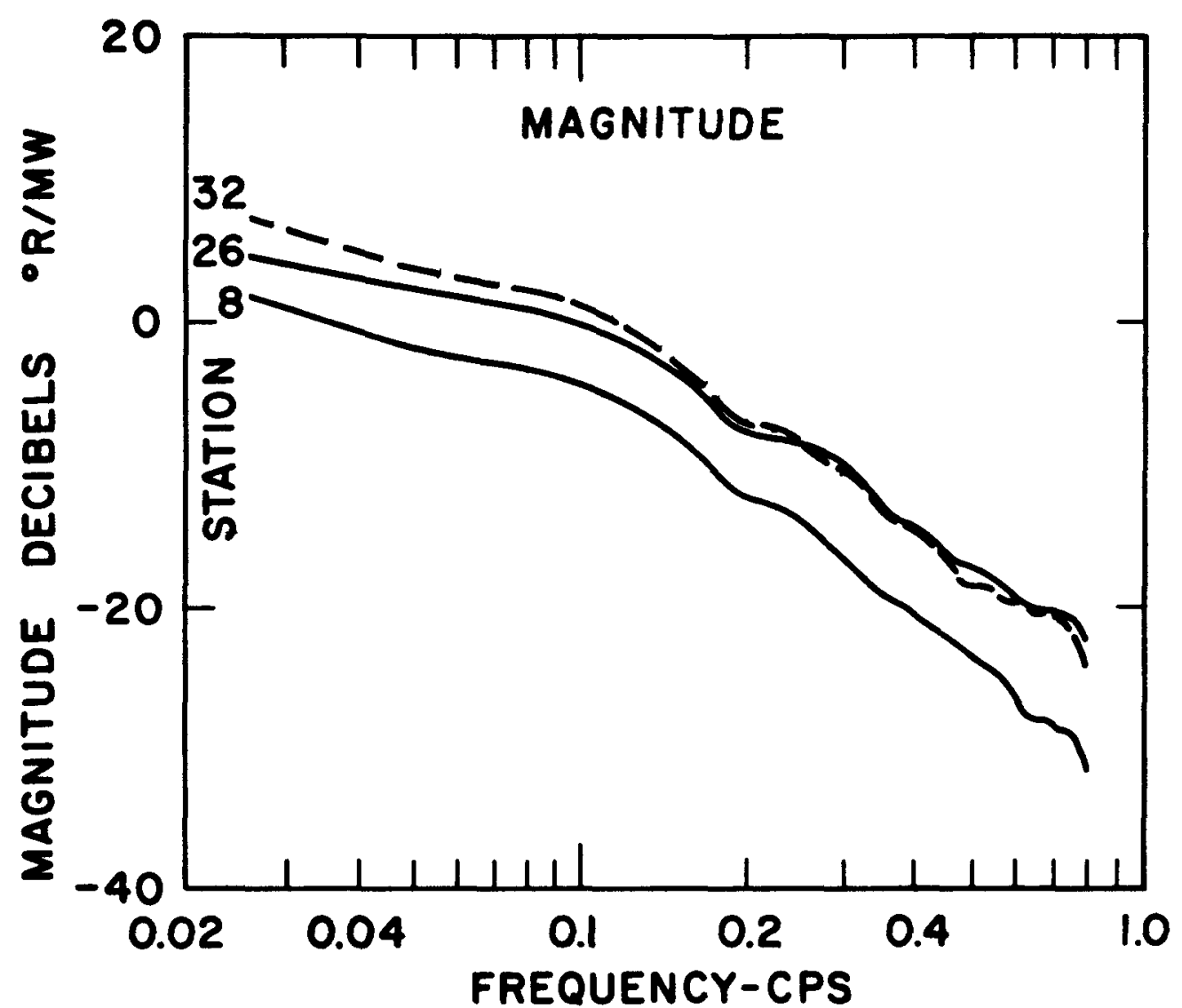

Figure 4. KIWI-B-4E Power-to-Core Temperature Transfer Function

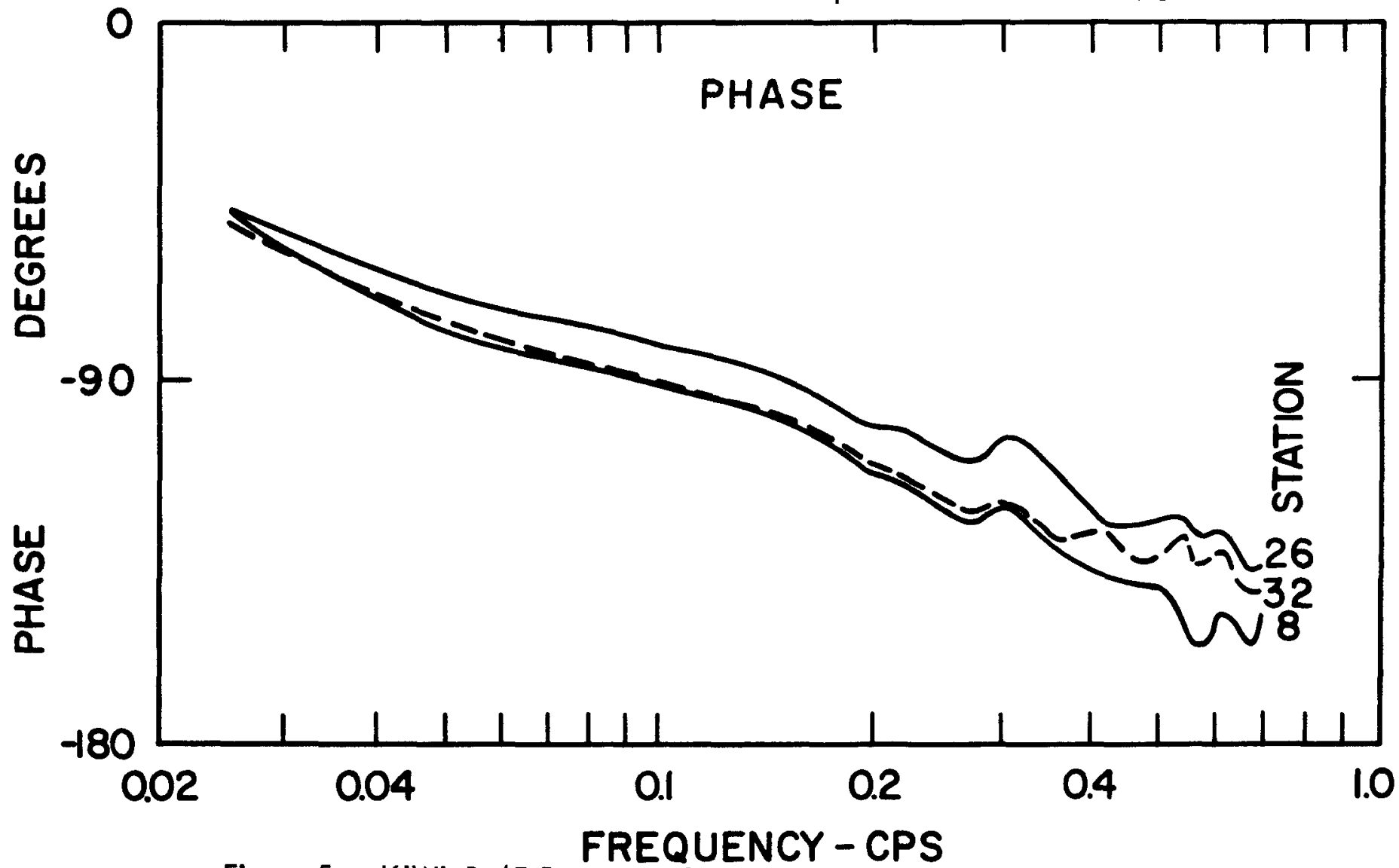

Figure 5. KIWI-B-4E Power-fo-Core Temperature Transfer Function 


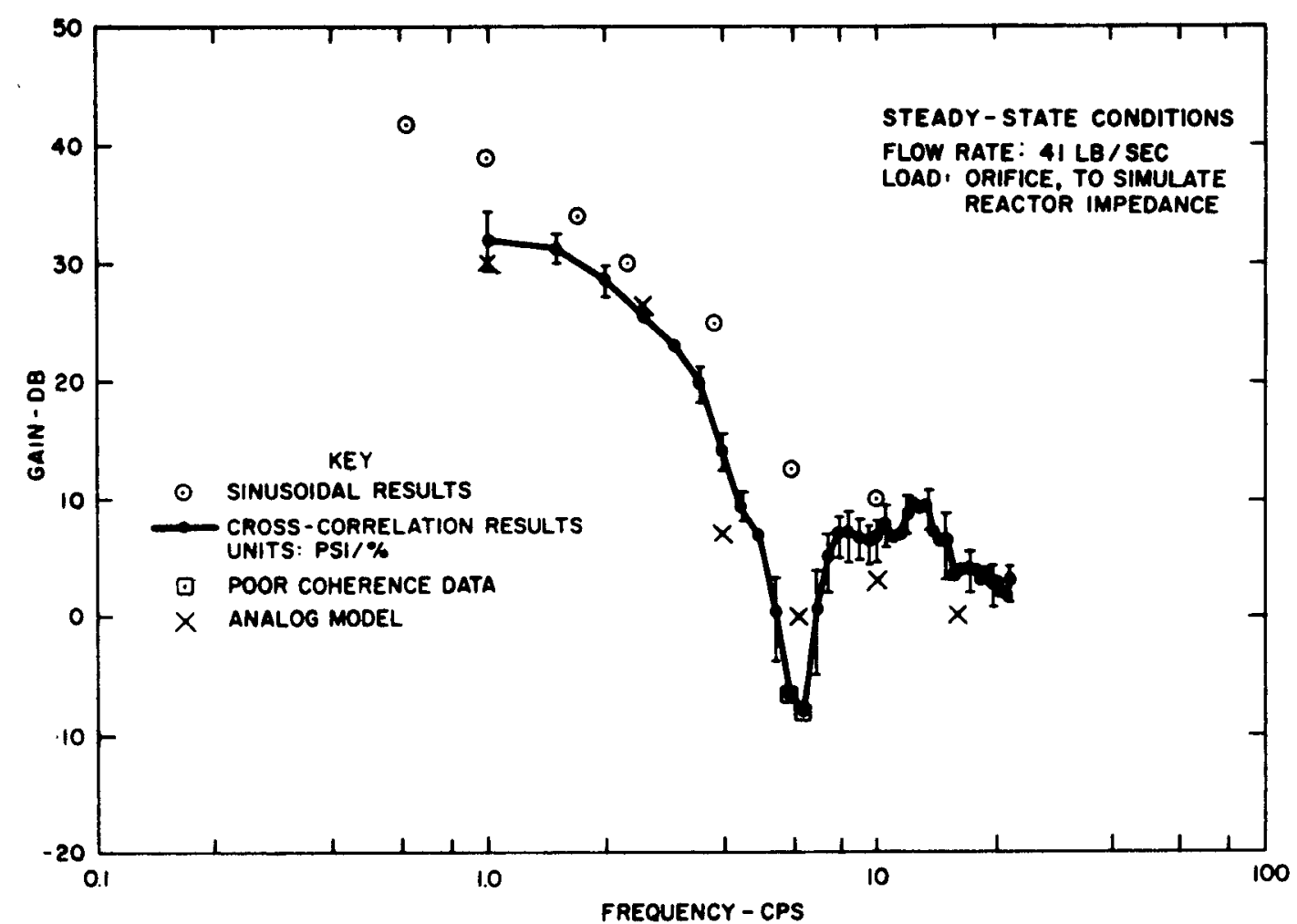

Figure 6. Transfer Function Gain: Pump Exit Pressure/PCV-50 Valve Position; NRX-A3 EP-II-FC Data

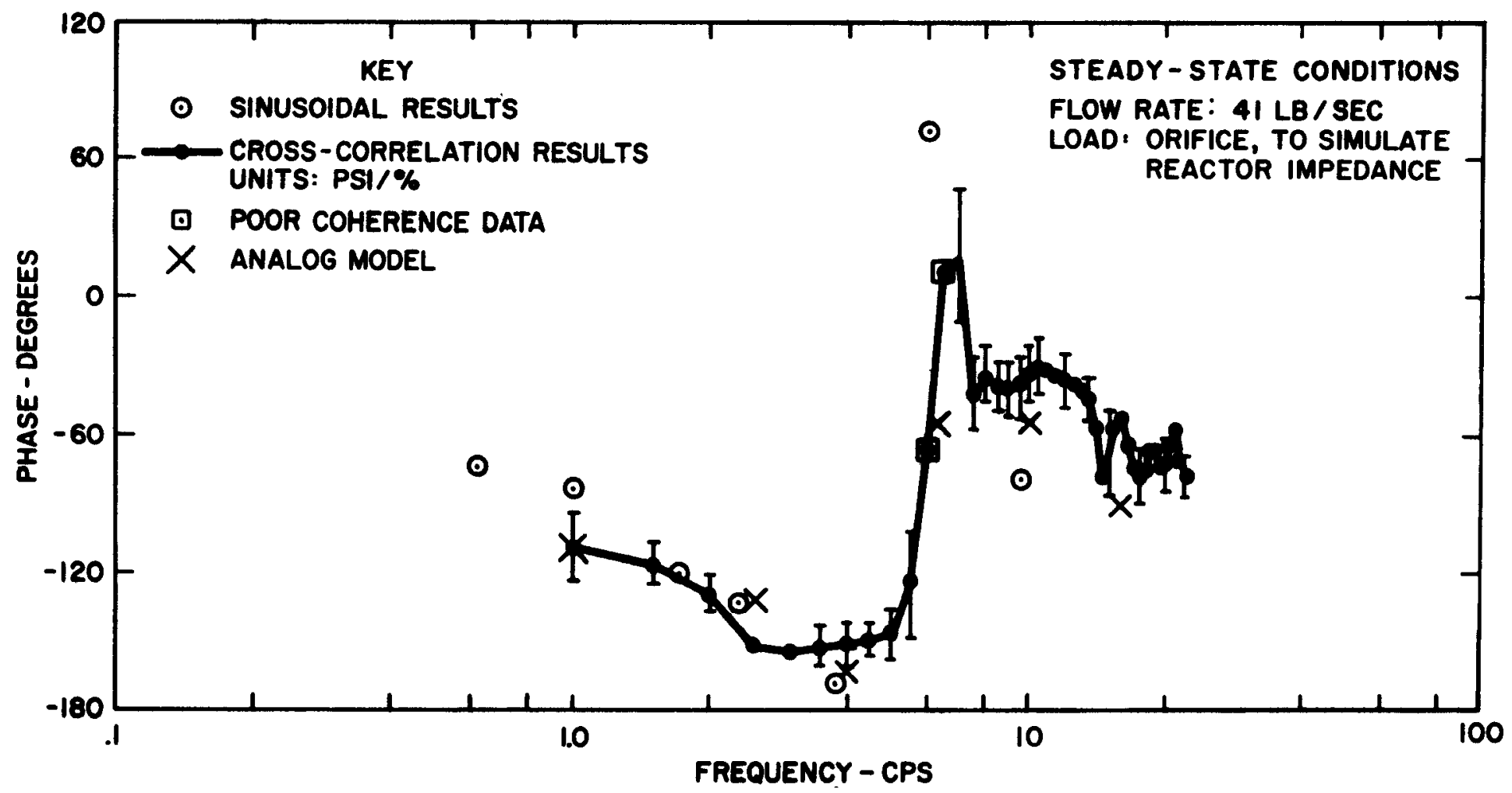

Figure 7. Transfer Function Phase: Pump Exit Pressure/PCV-50 Valve Position; NRX-A3 EP-II-FC Data 


\section{KEY}

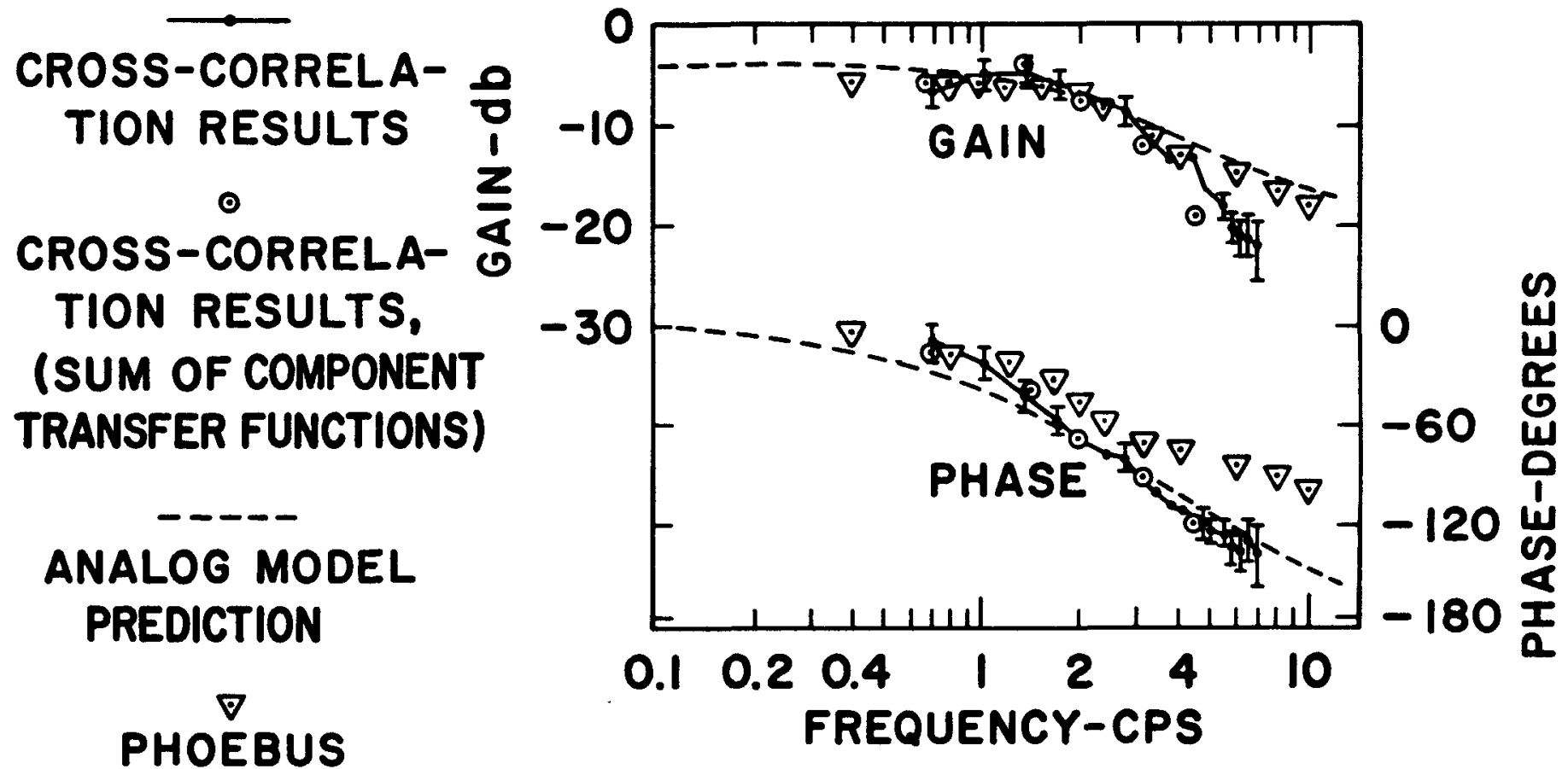

\section{IA RESULTS}

Figure 8. Transfer Function: Nozzle Chamber Pressure/Feedling Exit Pressure; NRX-A3 EP-IV, Phoebus IA, and Analog Model

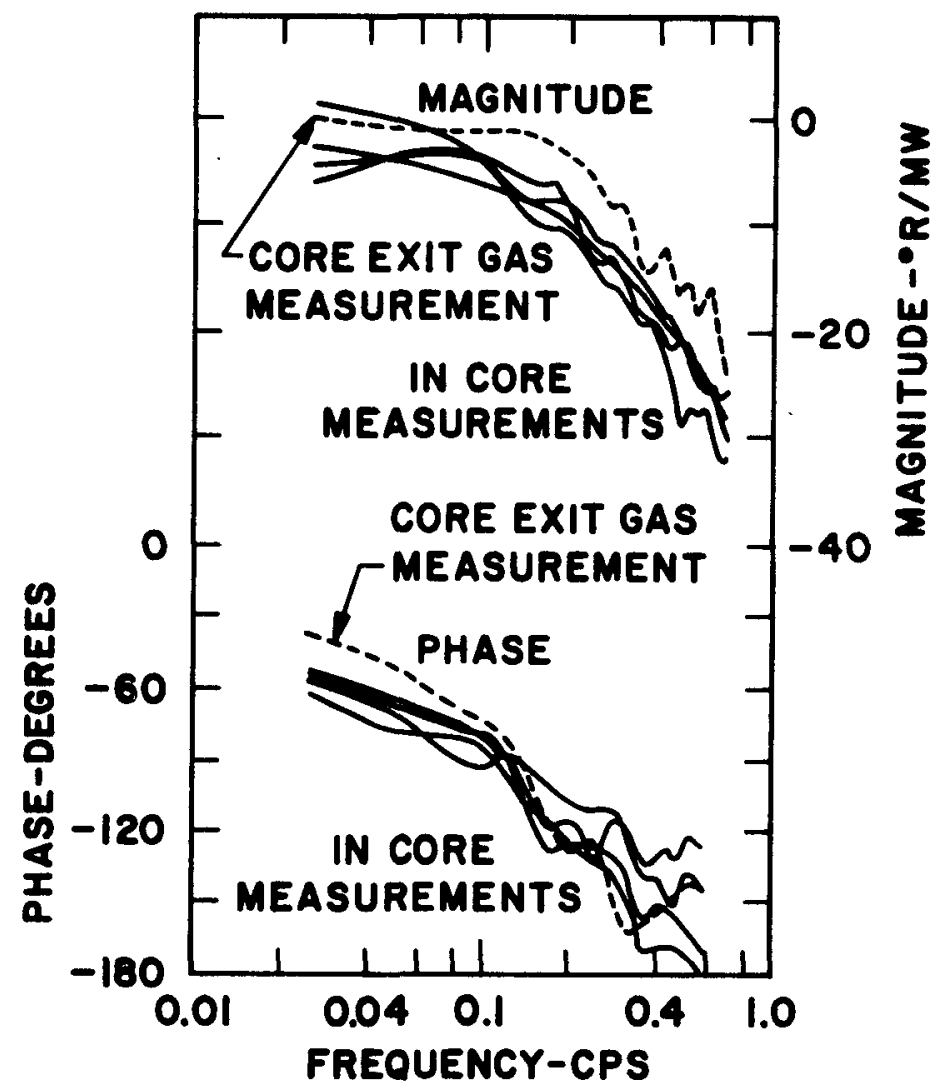

Figure 9. Phoebus I-A Power-to-Temperature Transfer Function 


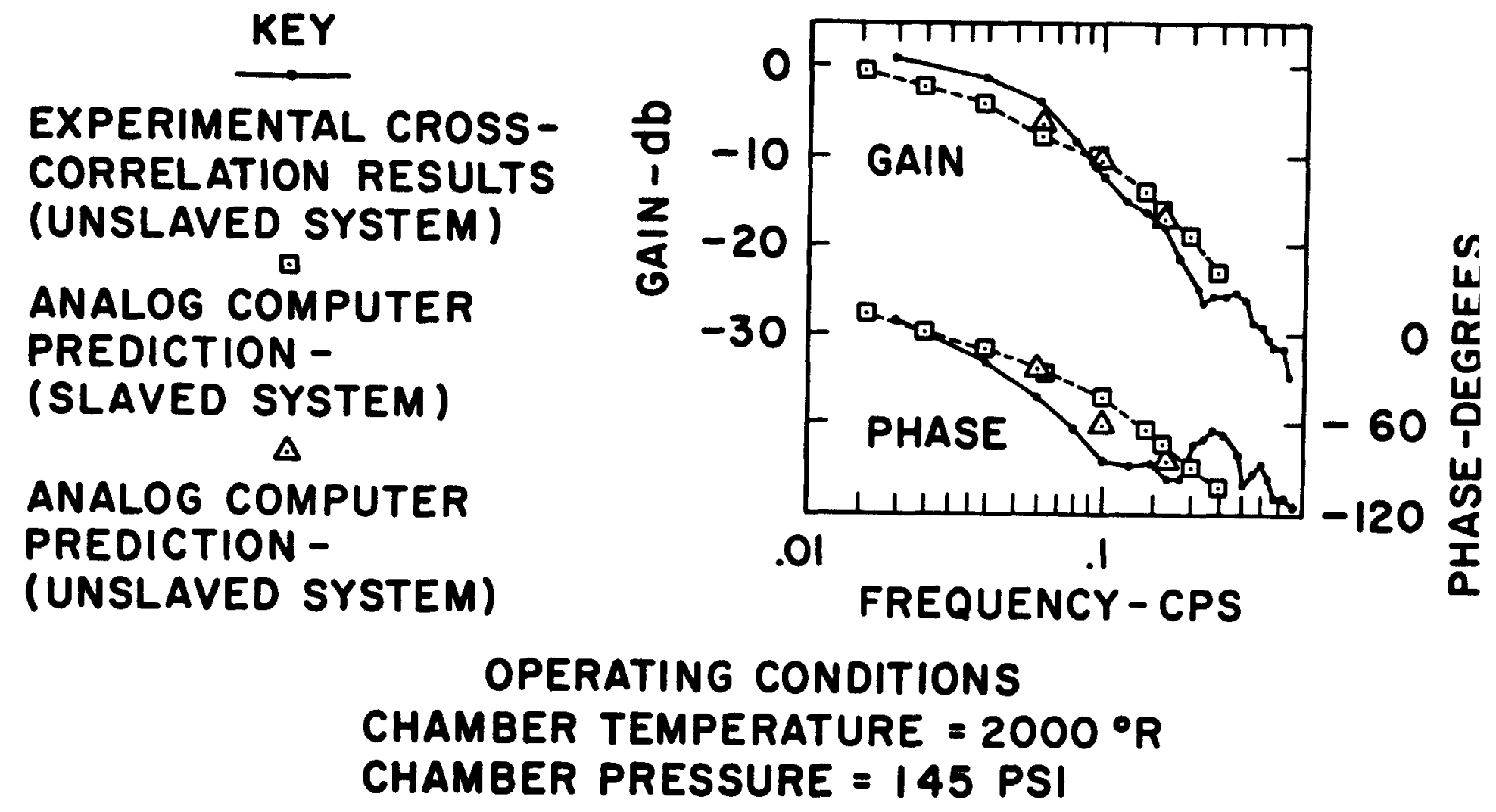

Figure 10. Comparison of the Predicted and Measured Transfer Function for Chamber Temperature/Chamber Temperature Demand for the No Flux Loop Temperature Controller, NRX/EST EP-IIC 